\title{
Sol-Gel-Derived Glass-Ceramic Photorefractive Films for Photonic Structures
}

\author{
Anna Lukowiak 1,*, Lidia Zur 2,3, Thi Ngoc Lam Tran 3,4,5, Marcello Meneghetti 3,6, \\ Simone Berneschi ${ }^{7}$, Gualtiero Nunzi Conti ${ }^{7}$, Stefano Pelli ${ }^{7}$, Cosimo Trono ${ }^{7}$, \\ B.N. Shivakiran Bhaktha ${ }^{8}$, Daniele Zonta ${ }^{2,4,9}$, Stefano Taccheo ${ }^{10}$, Giancarlo C. Righini ${ }^{2,7}$ \\ and Maurizio Ferrari ${ }^{2,3}$ \\ 1 Institute of Low Temperature and Structure Research, PAS, 2 Okolna St., 50-422 Wroclaw, Poland \\ 2 Centro di Studi e Ricerche “Enrico Fermi”, Piazza del Viminale 1, 00184 Roma, Italy; zur@fbk.eu (L.Z.); \\ daniele.zonta@unitn.it (D.Z.); giancarlo.righini@centrofermi.it (G.C.R.); maurizio.ferrari@cnr.it (M.F.) \\ 3 IFN-CNR CSMFO Lab., and FBK Photonics Unit via alla Cascata 56/C Povo, 38123 Trento, Italy; \\ thitran@fbk.eu (T.N.L.T.); Marcello.Meneghetti@studenti.unitn.it (M.M.) \\ 4 DICAM Department of Civil, Environmental and Mechanical Engineering, University of Trento, \\ Via Mesiano, 77, 38123 Trento, Italy \\ 5 Ho Chi Minh City University of Technical Education, 1 Vo Van Ngan Street, Linh Chieu Ward, \\ Thu Duc District, Ho Chi Minh City, Vietnam \\ 6 Department of Physics, Via Sommarive 14, Povo, 38123 Trento, Italy \\ 7 CNR-IFAC Via Madonna del Piano, 10, 50019 Sesto Fiorentino, FI, Italy; bernes@ifac.cnr.it (S.B.); \\ g.nunziconti@ifac.cnr.it (G.N.C.); s.pelli@ifac.cnr.it (S.P.); c.trono@ifac.cnr.it (C.T.) \\ 8 Department of Physics, Indian Institute of Technology Kharagpur, Kharagpur 721302, India; \\ kiranbhaktha@gmail.com \\ 9 University of Strathclyde Glasgow, 16 Richmond St, Glasgow G1 1XQ, UK \\ 10 College of Engineering, Swansea University, Singleton Park, Swansea SA2 8PP, UK; \\ S.Taccheo@swansea.ac.uk \\ * Correspondence: A.Lukowiak@int.pan.wroc.pl; Tel.: +48-71-3954190
}

Academic Editors: Rui M. Almeida and Luís F. Santos

Received: 5 January 2017; Accepted: 17 February 2017; Published: 21 February 2017

\begin{abstract}
Glass photonics are widespread, from everyday objects around us to high-tech specialized devices. Among different technologies, sol-gel synthesis allows for nanoscale materials engineering by exploiting its unique structures, such as transparent glass-ceramics, to tailor optical and electromagnetic properties and to boost photon-management yield. Here, we briefly discuss the state of the technology and show that the choice of the sol-gel as a synthesis method brings the advantage of process versatility regarding materials composition and ease of implementation. In this context, we present tin-dioxide-silica $\left(\mathrm{SnO}_{2}-\mathrm{SiO}_{2}\right)$ glass-ceramic waveguides activated by europium ions $\left(\mathrm{Eu}^{3+}\right)$. The focus is on the photorefractive properties of this system because its photoluminescence properties have already been discussed in the papers presented in the bibliography. The main findings include the high photosensitivity of sol-gel $25 \mathrm{SnO}_{2}: 75 \mathrm{SiO}_{2}$ glass-ceramic waveguides; the ultraviolet (UV)-induced refractive index change $\left(\Delta n \sim-1.6 \times 10^{-3}\right)$, the easy fabrication process, and the low propagation losses $(0.5 \pm 0.2 \mathrm{~dB} / \mathrm{cm})$, that make this glass-ceramic an interesting photonic material for smart optical applications.
\end{abstract}

Keywords: sol-gel; $\mathrm{SnO}_{2}-\mathrm{SiO}_{2}$; transparent glass-ceramics; photorefractivity; planar waveguides; attenuation coefficient; Lorentz-Lorenz formula 


\section{Introduction}

Glass photonics are prevalent in many human activities and are a crucial factor for enabling technology research. The fruitful exploitation of glass photonics provides a large spectrum of applications, covering Health and Biology, Structural Engineering, and Environment Monitoring Systems, that have been developed during the last years. Among the different glass-based systems, transparent glass-ceramics offer specific characteristics of capital importance in photonics [1]. Glass-ceramics are a class of composite materials formed by nanometer-up to micrometer-sized crystals dispersed in a glassy matrix [2]. The respective composition and the volume fractions of crystalline and amorphous phases determine the glass-ceramic properties. Nanocrystals, when activated by luminescent species, such as rare earth ions, make the spectroscopic properties of the glass-ceramic very attractive [3]. In comparison to glass, such systems can be characterized by higher absorption and emission cross sections, lower phonon cut-off energy, and better control of the rare earth ion-ion interaction. These properties are of particular interest for waveguiding systems [4].

Glass-ceramic waveguides with luminescent properties are effective optical media to investigate the basic mechanisms and to develop the technologies related to light propagation in composite materials and luminescence enhancement. The principal argument of discussion concerns the basic mechanism allowing fabrication of transparent glass-ceramic waveguides. A clear and exhaustive theory of transparency in nanocomposite systems is an important step to overcome a crucial technological bottleneck for the fabrication of integrated optical devices and novel fiber lasers [5]. If we pay attention to the current state of the technology, it appears evident that, together with the transparency, the luminescence efficiency in the luminescent glass-ceramic photonic circuits appears as another topical challenge.

In previous papers we have discussed the crystallization effect in tin-dioxide-silica $\left(\mathrm{SnO}_{2}-\mathrm{SiO}_{2}\right)$ transparent glass-ceramics and their unique luminescent properties when activated by rare earth ions for photon management [6-13]. Phorefractivity is another important property of tin dioxide $\left(\mathrm{SnO}_{2}\right)$ based glasses. In respect to the well-known germanium ions doping, tin ions represent a promising alternative because many devices, such as Bragg gratings, present a higher thermal stability in this matrix than in the germania-silica $\left(\mathrm{GeO}_{2}-\mathrm{SiO}_{2}\right)$ network [14,15]. The research regarding refractive index modification by laser irradiation is very active as evidenced by several papers approaching the topic with several different techniques [16,17].

In the following report we present consolidated outcomes, novel results, and perspectives for $\mathrm{SnO}_{2}$-based glass-ceramic waveguides, obtained by the sol-gel route with top-down approach. The top-down approach seeks to create nanocomposite devices by using larger, externally-controlled zones to develop a new system, while the bottom-up approach seeks to get smaller components and arrange them into a more complex system. Moreover, the change of refractive index induced by laser irradiation of glass-ceramics will be discussed.

\section{Results}

Tin-silica glass-ceramic waveguides discussed here had a nominal composition of $25 \mathrm{SnO}_{2}: 75 \mathrm{SiO}_{2}$ $\mathrm{mol} \%$ and were activated by $1 \mathrm{~mol} \%$ of europium ions $\left(\mathrm{Eu}^{3+}\right)$. The slab waveguides supported two modes at $635 \mathrm{~nm}$ and only one mode at $1550 \mathrm{~nm}$. The experimentally evaluated value for the film thickness was equal to $1.04 \mu \mathrm{m}( \pm 0.1 \mu \mathrm{m})$ and the refractive index was $1.5578( \pm 0.0005)$ at $635 \mathrm{~nm}$ and $1.5323( \pm 0.0003)$ at $1550 \mathrm{~nm}$. With the photometric detection method, a loss value of $0.5 \pm 0.2 \mathrm{~dB} / \mathrm{cm}$ was measured.

The change of the refractive index of these films induced by the ultraviolet (UV) exposure was calculated by measuring, after each irradiation, the change of the effective indices of the modes of the film acting as a slab waveguide. This procedure was followed for the two modes supported at $635 \mathrm{~nm}$. The change of the effective index of the single mode supported at $1550 \mathrm{~nm}$ was also monitored.

Figure 1 shows the resulting index change $\Delta n$ as a function of the cumulative doses used; the two series of data correspond to the change of the effective index of the single mode at $1550 \mathrm{~nm}$ (squares) 
and to the change of the film index at $635 \mathrm{~nm}$ (circles). The larger error for $\Delta n$ at $635 \mathrm{~nm}$, as indicated by the error bar, is due to the fact that the film index is reconstructed from the measurements of the effective indices of the two existing modes, while at $1550 \mathrm{~nm}$, one measures directly the $\Delta n$ for the effective index of the single supported mode.

The irradiations were made with pulse fluence of $38 \mathrm{~mJ} / \mathrm{cm}^{2}$ up to a cumulative dose of $1.5 \mathrm{~kJ} / \mathrm{cm}^{2}$ and with pulse fluence of $76 \mathrm{~mJ} / \mathrm{cm}^{2}$ for the higher cumulative doses. The measurements at both the wavelengths indicated a decrease of $\Delta n$ with increasing cumulative irradiated energy.

The saturation value for the index modulation was around $-1.6 \times 10^{-3}$ and it was reached at a dose of $7.6 \mathrm{~kJ} / \mathrm{cm}^{2}$. This refractive index change is of the same order as that obtained in a $\mathrm{SnO}_{2}-\mathrm{Na}_{2} \mathrm{O}-\mathrm{SiO}_{2}$ melted glass [14] and that observed in sol-gel-derived $\mathrm{SnO}_{2}-\mathrm{SiO}_{2}$ nanostructured glass [18].

At $248 \mathrm{~nm}$, a slight decrease of the absorption coefficient $\alpha$, from $6.27 \times 10^{3} \mathrm{~cm}^{-1}$ to $5.44 \times 10^{3} \mathrm{~cm}^{-1}$, was measured before and after a cumulative UV irradiation dose of $7.6 \mathrm{~kJ} / \mathrm{cm}^{2}$.

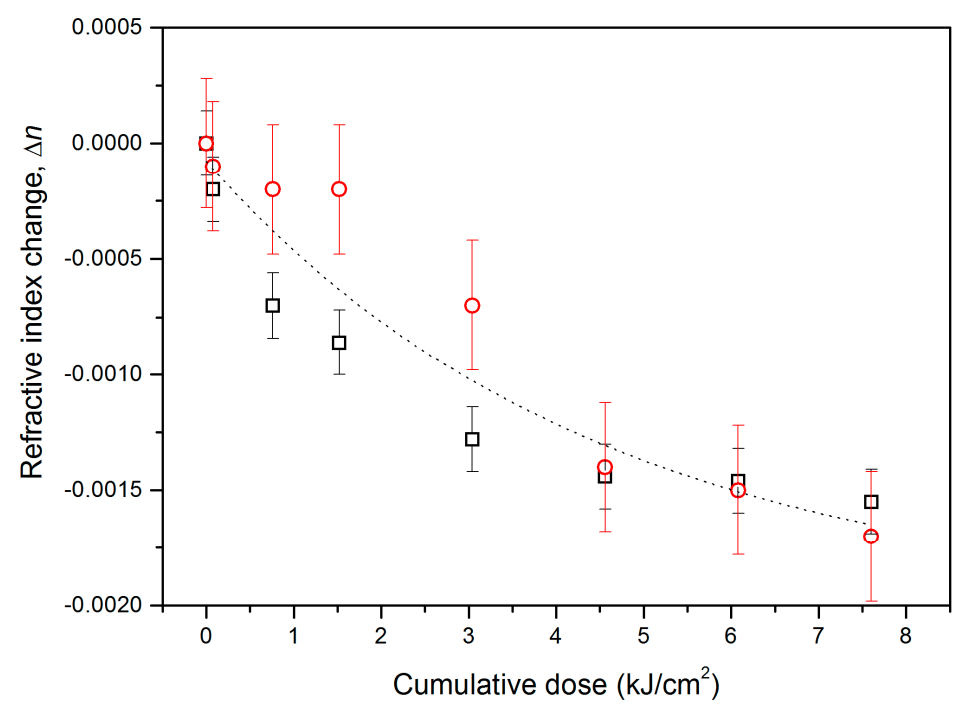

Figure 1. The effective refractive index change of the $\mathrm{SnO}_{2}-\mathrm{SiO}_{2}$ film at $1550 \mathrm{~nm}$ (squares) and at $635 \mathrm{~nm}$ (circles), measured on a slab waveguide after ultraviolet (UV) irradiation at $248 \mathrm{~nm}$, as a function of cumulative dose. The error bars are $\pm 2.8 \times 10^{-4}$ and $\pm 1.4 \times 10^{-4}$ for the $\Delta n$ of the film and the mode, respectively. The dashed exponential curve is a guide for the eye.

\section{Discussion}

The value of the refractive index change is high enough not only to write gratings but also to allow for the direct imprint of integrated optical waveguides. In fact, by taking advantage of the vertical confinement provided by the film itself, it is sufficient to irradiate the side area using a photomask and, thus, produce a channel waveguide by decreasing the index around it. Indeed, at $635 \mathrm{~nm}$ and at lower wavelengths, for example, corresponding to the ${ }^{5} \mathrm{D}_{0} \rightarrow{ }^{7} \mathrm{~F}_{2}$ emission of Eu ${ }^{3+}$ ions (613 nm) [7], the index change is high enough to allow the lateral confinement of the light.

In order to better understand the effect of the UV irradiation on the structure of the film, we performed an additional exposure using a metal copper wire with a diameter of $85 \mu \mathrm{m}$ to mask the sample. The irradiation parameters were as follows: $76 \mathrm{~mJ} / \mathrm{cm}^{2}$ pulse fluence; $10 \mathrm{~Hz}$ repetition rate; and $10^{5}$ pulses $\left(7.6 \mathrm{~kJ} / \mathrm{cm}^{2}\right.$ cumulative dose). After the exposure, we removed the wire and scanned the sample surface with a stylus profilometer (TENCOR P-10, Milpitas, CA, USA). An increase in the film thickness, $T$, of about $4 \mathrm{~nm}$ was effectively measured in the irradiated region. The correlation between the change, $\Delta T$, in the film thickness and the refractive index change, $\Delta n$, can be obtained by differentiating the Lorentz-Lorenz formula [15]. 


$$
\frac{\Delta n}{n}=\frac{\left(n^{2}-1\right)\left(n^{2}+2\right)}{6 n^{2}}\left[-\frac{\Delta T}{T}+\frac{\Delta \alpha}{\alpha}\right]
$$

where $n$ is the refractive index and $\alpha$ is the bond polarizability. From Equation (1), the contribution of volume expansion yields a calculated refractive index reduction of $2.6 \times 10^{-3}$, whereas the experimental value is about $1.6 \times 10^{-3}$. This result suggests that the material polarizability contributes to the effective index change $\left(\Delta n_{\mathrm{pol}} \approx+1.0 \times 10^{-3}\right.$ for a cumulative dose of $\left.7.6 \mathrm{~kJ} / \mathrm{cm}^{2}\right)$ and competes with that of the volume expansion, partially compensating for the latter effect.

Determination of the propagation losses was impossible due to the short length of the photostructured region $(\sim 1 \mathrm{~cm})$. Comparison of the mode resonance dips measured at $635 \mathrm{~nm}$ and $1550 \mathrm{~nm}$ in the same coupling conditions showed no changes in the resonance width. This indicated that there were no appreciable changes in the film propagation loss. Moreover, no differences were observed in the $\mathrm{Eu}^{3+}$ photoluminescence spectra in irradiated and non-irradiated zones.

\section{Materials and Methods}

Tin-silica glass-ceramic waveguides presented here had a nominal composition of $25 \mathrm{SnO}_{2}: 75 \mathrm{SiO}_{2}$ (mol\%) with $1 \mathrm{~mol} \%$ of $\mathrm{Eu}^{3+}$ ions and were prepared by the sol-gel method. The starting solution was obtained by mixing tetraethylorthosilicate (TEOS), ethanol $(\mathrm{EtOH})$, deionized water $\left(\mathrm{H}_{2} \mathrm{O}\right)$, and hydrochloric acid $(\mathrm{HCl})$ as a catalyst, and was prehydrolyzed for $1 \mathrm{~h}$ at $65{ }^{\circ} \mathrm{C}$. The molar ratio of TEOS: $\mathrm{HCl}: \mathrm{EtOH}: \mathrm{H}_{2} \mathrm{O}$ was 1:0.01:37.9:2. An ethanolic colloidal suspension, prepared using tin(II) chloride dihydrate $\left(\mathrm{SnCl}_{2} \cdot 2 \mathrm{H}_{2} \mathrm{O}\right)$ and europium(III) nitrate pentahydrate $\left(\mathrm{Eu}\left(\mathrm{NO}_{3}\right)_{3} \cdot 5 \mathrm{H}_{2} \mathrm{O}\right)$ as precursors, was added to the solution containing TEOS. The final mixture was left at room temperature, under stirring, for $16 \mathrm{~h}$. The resulting sol was filtered and then deposited on pure vitreous- $\mathrm{SiO}_{2}$ $\left(\mathrm{v}-\mathrm{SiO}_{2}\right)$ substrates by dip-coating, with a dipping rate of $60 \mathrm{~mm} / \mathrm{min}$. Each layer was annealed in air for $3 \mathrm{~min}$ at $800{ }^{\circ} \mathrm{C}$ prior to the next coat. After every five dips, the films were annealed for $5 \mathrm{~min}$ at $800{ }^{\circ} \mathrm{C}$. The films resulting from 20 coatings were stabilized by a treatment for $10 \mathrm{~min}$ at $800{ }^{\circ} \mathrm{C}$. Finally, a heat treatment at $1000{ }^{\circ} \mathrm{C}$ for $5 \mathrm{~h}$ in order to produce a glass-ceramic system was performed. Figure 2 shows the TEM picture of the prepared sample where $\mathrm{SnO}_{2}$ nanocrystals are clearly seen.

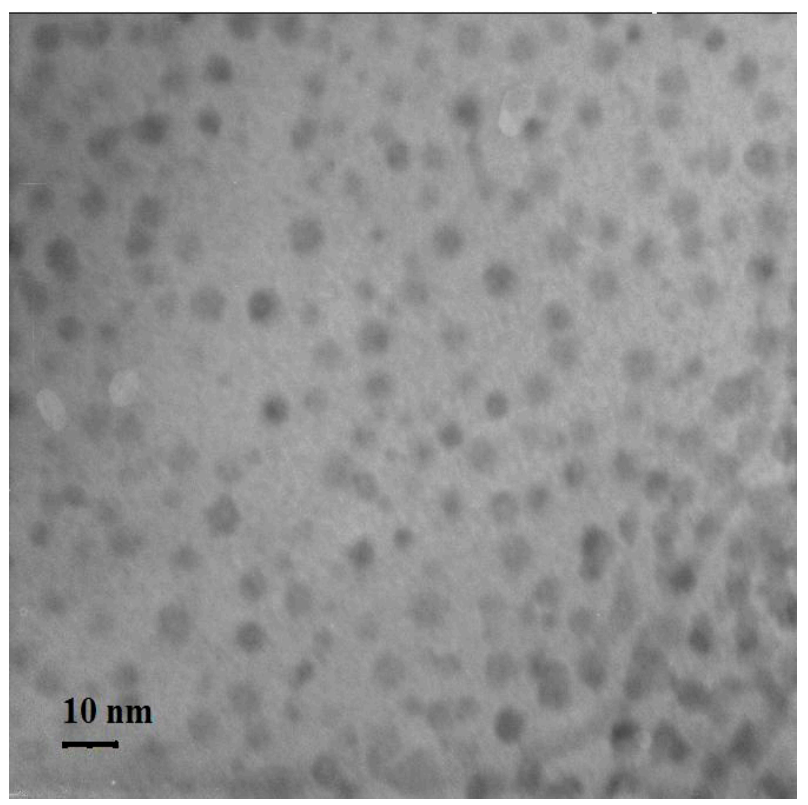

Figure 2. TEM images of the $1 \mathrm{~mol} \%$ europium ion $\left(\mathrm{Eu}^{3+}\right)$-doped $\mathrm{SnO}_{2}-\mathrm{SiO}_{2}$ glass-ceramic waveguide treated at $1000{ }^{\circ} \mathrm{C}$ for five hours showing tin dioxide $\left(\mathrm{SnO}_{2}\right)$ nanocrystals dispersed in the amorphous matrix. 
The guiding properties of the films were tested by the prism coupling technique, with a nominal resolution on the measured effective refractive index of about $5 \times 10^{-5}$. The apparatus is equipped with a piezoresistive pressure monitoring system that makes it possible to adjust the mechanical pressure between the prism and the sample during the coupling operation; this guarantees a very good reproducibility. The propagation losses at $633 \mathrm{~nm}$ were evaluated, for the $\mathrm{TE}_{0}$ (fundamental transverse electric) mode, by photometric detection of the light intensity coupled from a helium-neon ( $\mathrm{He}-\mathrm{Ne})$ laser and scattered out of the waveguide plane. The effect of exposure to UV laser radiation was studied by using a KrF excimer laser source (Lambda Physik Compex 110, Coherent Inc., Santa Clara, CA, USA) with an emission at $\lambda=248 \mathrm{~nm}$. Two single-pulse fluences of $38 \mathrm{~mJ} / \mathrm{cm}^{2}$ and $76 \mathrm{~mJ} / \mathrm{cm}^{2}$ were tested. The repetition rate was set at $10 \mathrm{~Hz}$. Moreover, in order to obtain a good repeatability of the measurements, the sample was sandwiched between two home-made metal masks (Figure 3a). The overall system was removable from its holder in order to perform the optical characterization. The experimental apparatus setup used for the UV irradiation is shown in Figure 3b. The target section was constituted by a black metal panel with a fissure having a size close to that of the metal mask. This panel was positioned in front of the sample holder and the two openings were adequately aligned. In this way, any possible refractive index change due to the UV irradiation on the other unmasked part of the sample was avoided.
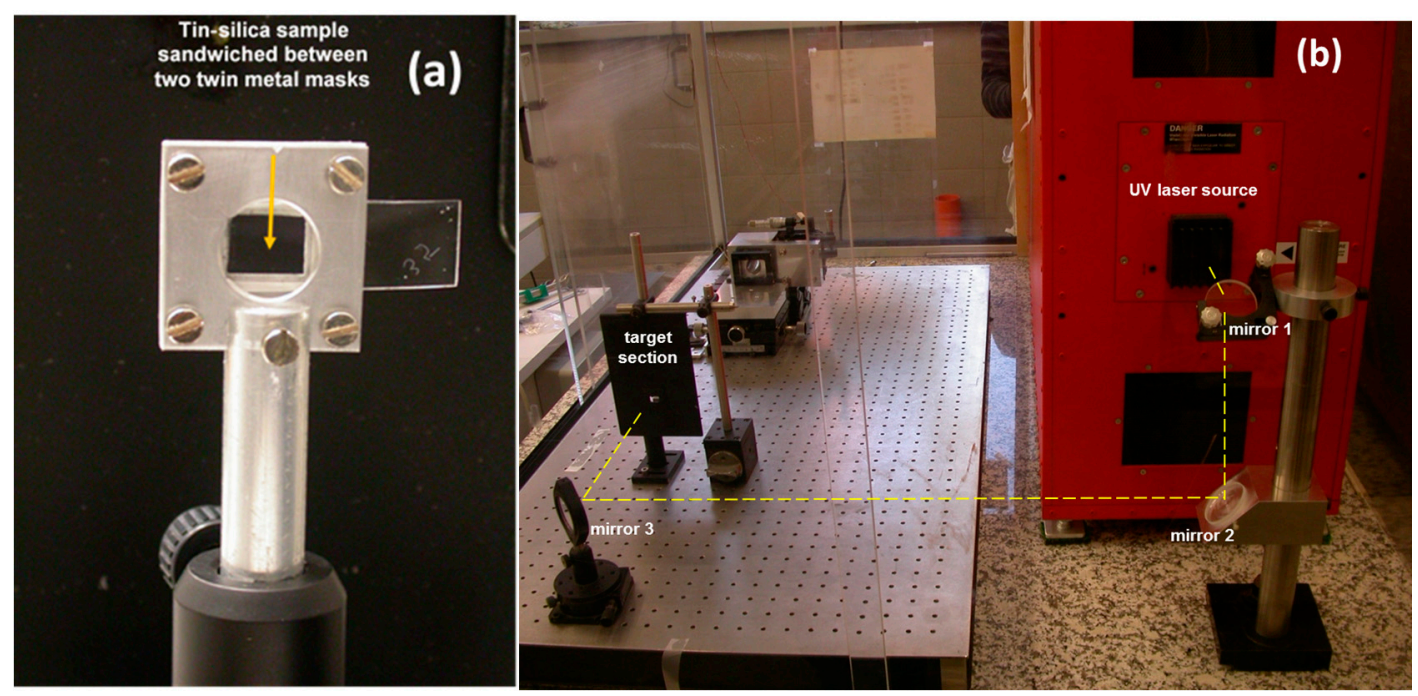

Figure 3. (a) $\mathrm{The} \mathrm{SnO}_{2}-\mathrm{SiO}_{2}$ waveguide sandwiched between two twin metal masks; (b) The experimental apparatus setup used for the UV irradiation of the $\mathrm{SnO}_{2}-\mathrm{SiO}_{2}$ sample.

The unmasked region of the material had an area of about $1.11 \times 0.88 \mathrm{~cm}^{2}$, close to that of the base of the prism used for dark-line spectroscopy. In this way, we were able to guarantee (i) a uniform irradiation for the unmasked area during the UV laser exposure; and (ii) a minimization of the error linked to the possibility of changing the coupling point during the dark-lines measurements. Statistical treatment of data sampling, based on the standard deviation, was carried out with a final uncertainty on the effective refractive index of about $1 \times 10^{-4}$.

The UV absorption spectra were recorded using an UV-VIS spectrophotometer (Varian Cary 100 Bio, Palo Alto, CA, USA) with a resolution of $1.4 \mathrm{~nm}$. The measurements were performed in the absorption mode through the thin films deposited on pure silica substrates.

$\mathrm{Eu}^{3+}$ photoluminescence was measured on the UV irradiated and on the non-irradiated portions of our samples and the emission spectra were compared. The measurements were done in waveguide configuration by exciting the $\mathrm{TE}_{0}$ mode [19] with the third harmonic of Nd:YAG at $355 \mathrm{~nm}$. We studied this indirect excitation mechanism of the $\mathrm{Eu}^{3+}$ ions in the $\mathrm{SnO}_{2}-\mathrm{SiO}_{2}$ systems in previous 
papers $[7,8,12,13]$ where we also discussed how the photoluminescence spectra can be used in order to assess the glass-ceramic structure.

\section{Conclusions}

Transparent glass-ceramic systems are crucial for photonics applications, especially in integrated optics. The important aspects in these nanocomposites when activated with rare earth ions are high luminescence efficiency and low attenuation losses. Additionally, photopatternable properties increase their applicability. The structures might be used for lasing, lightning, frequency converters, and sensing.

In conclusion, we have demonstrated high photosensitivity in sol-gel-derived $25 \mathrm{SnO}_{2}: 75 \mathrm{SiO}_{2}$ glass-ceramic waveguides doped with $1 \mathrm{~mol} \%$ of $\mathrm{Eu}^{3+}$. The easy fabrication process, the low propagation loss, and the UV-induced refractive index change $\left(\Delta n \approx-1.6 \times 10^{-3}\right)$, which enables the direct writing of both channel waveguides and Bragg gratings, make this glass a promising material for the low-cost development of efficient and multifunctional circuits for smart optical applications.

It has to be noted that the photorefractive behavior of $x \mathrm{SnO}_{2}:(1-x) \mathrm{SiO}_{2}$ glass-ceramic waveguides deserves further experiments to be completely understood.

Optimization of the sol-gel synthesis process for the creation of materials tailored for the specific application and of the confined structure fabrication technologies may guarantee that new record performances of rare earth-doped glass-ceramic-based photonic devices will be achieved.

Acknowledgments: This research is performed in the framework of the COST Action MP1401 "Advanced Fibre Laser and Coherent Source as tools for Society, Manufacturing and Lifescience" (2014-2018) and of the projects PAS-CNR (2014-2016) and PLESC-PLANS-Centro Fermi. S. Berneschi acknowledges the European Community for its funding within the framework of the project Hemospec "Advanced spectroscopic hemogram for personalized care against life-threatening infections using an integrated chip-assisted bio-photonic system" (FP7-611682). The authors are very grateful to all the colleagues who are involved in the research on photonics glass-ceramics, and in particular to C. Armellini, A. Chiasera, A. Chiappini, S. Varas, A. Carpentiero, M. Mazzola (IFN-CNR \& FBK), B. Boulard, C. Duverger (Université du Maine), A. Martucci (University of Padova), F. Prudenzano (Politecnico di Bari), D. Ristic (Ruder Boskovic Institute), F. Scotognella (Politecnico Milano), and A. Vaccari (FBK).

Author Contributions: A.L., M.F., and G.C.R. conceived the idea of developing glass-ceramic waveguides based on $\mathrm{SnO}_{2}$ and designed the experiments to assess the photonic properties; L.Z., T.N.L.T., B.N.S.B., and M.M. fabricated and characterized the waveguides; S.B., G.N.C., C.T., and S.P. performed UV irradiation and collaborated in refractive index measurements; D.Z. and S.T. applied theoretical calculations to estimate the waveguiding properties and analyzed the data. All authors discussed the experimental implementation and results and contributed to writing the paper.

Conflicts of Interest: The authors declare no conflict of interest.

\section{References}

1. Zanotto, E.D. A bright future for glass-ceramics. Am. Ceram. Soc. Bull. 2010, 89, 19-27.

2. De Pablos-Martin, A.; Ferrari, M.; Pascual, M.J.; Righini, G.C. Glass-ceramics: A class of nanostructured materials for photonics. Riv. Nuovo Cimento 2015, 38, 311-369.

3. Lukowiak, A.; Chiasera, A.; Chiappini, A.; Righini, G.C.; Ferrari, M. Active sol-gel materials, fluorescence spectra and lifetimes. In Handbook of Sol-Gel Science and Technology: Processing, Characterization and Applications, 2nd ed.; Klein, L., Aparicio, M., Jitianu, A., Eds.; Springer: New York, NY, USA, 2017; pp. 1-43.

4. Ferrari, M.; Righini, G.C. Glass-ceramic materials for guided-wave optics. Int. J. Appl. Glass Sci. 2015, 6, 240-248. [CrossRef]

5. Materials, Physical and Nanosciences COST Action MP1401: Advanced Fibre Laser and Coherent Source as Tools for Society, Manufacturing and Lifescience. Available online: http:/ /www.aflaser.eu/ (accessed on 15 December 2016).

6. Gonçalves, R.R.; Ferrari, M.; Chiasera, A.; Montagna, M.; Morais, E.A.; Schalvi, L.V.A.; Santilli, C.V.; Messaddeq, Y.; Ribeiro, S.J.L. Planar waveguides based on nanocrystalline and $\mathrm{Er}^{3+}$ doped $\mathrm{SnO}_{2}$. Mater. Sci. Forum 2002, 403, 107-110. [CrossRef] 
7. Bhaktha, S.N.B.; Beclin, F.; Bouazaoui, M.; Capoen, B.; Chiasera, A.; Ferrari, M.; Kinowski, C.; Righini, G.C.; Robbe, O.; Turrell, S. Enhanced fluorescence from $\mathrm{Eu}^{3+}$ in low-loss silica glass-ceramic waveguides with high $\mathrm{SnO}_{2}$ content. Appl. Phys. Lett. 2008, 93, 211904. [CrossRef]

8. Bhaktha, S.N.B.; Kinowski, C.; Bouazaoui, M.; Capoen, B.; Robbe-Cristini, O.; Beclin, F.; Roussel, P.; Ferrari, M.; Turrell, S. Controlled growth of $\mathrm{SnO}_{2}$ nanocrystals in $\mathrm{Eu}^{3+}$-doped $\mathrm{SiO}_{2} / \mathrm{SnO}_{2}$ planar-waveguides: A spectroscopic investigation. J. Phys. Chem. C 2009, 113, 21555-21559. [CrossRef]

9. Van Tran, T.; Turrell, S.; Eddafi, M.; Capoen, B.; Bouazaoui, M.; Roussel, P.; Berneschi, S.; Righini, G.C.; Ferrari, M.; Bhaktha, S.N.B.; et al. Investigations of the effects of the growth of $\mathrm{SnO}_{2}$ nanoparticles on the structural properties of glass-ceramic planar waveguides using Raman and FTIR spectroscopies. J. Mol. Struct. 2010, 976, 314-319. [CrossRef]

10. Bhaktha, B.N.S.; Berneschi, S.; Nunzi Conti, G.; Righini, G.C.; Chiappini, A.; Chiasera, A.; Ferrari, M.; Turrell, S. Spatially localized UV-induced crystallization of $\mathrm{SnO}_{2}$ in photorefractive $\mathrm{SiO}_{2}-\mathrm{SnO}_{2}$ thin film. Proc. SPIE 2010, 7719. [CrossRef]

11. Van Tran, T.T.; Turrell, S.; Capoen, B.; Van Hieu, L.; Ferrari, M.; Ristic, D.; Boussekey, L.; Kinowski, C. Environment segregation of $\mathrm{Er}^{3+}$-emission in bulk sol-gel-derived $\mathrm{SiO}_{2}-\mathrm{SnO}_{2}$ glass ceramics. J. Mater. Sci. 2014, 49, 8226-8233. [CrossRef]

12. Van Tran, T.T.; Turrell, S.; Capoen, B.; Vinh, L.Q.; Cristini-Robbe, O.; Bouazaoui, M.; d'Acapito, F.; Ferrari, M.; Ristic, D.; Lukowiak, A.; et al. Erbium-doped tin-silicate sol-gel-derived glass-ceramic thin films: Effect of environment segregation on the $\mathrm{Er}^{3+}$ emission. Sci. Adv. Mater. 2015, 7, 301-308. [CrossRef]

13. Zur, L.; Tran, T.N.L.; Meneghetti, M.; Tran, T.T.V.; Lukowiak, A.; Chiasera, A.; Zonta, D.; Ferrari, M.; Righini, G.C. Tin-dioxide nanocrystals as $\mathrm{Er}^{3+}$ luminescence sensitizers: Formation of glass-ceramics thin films and their characterization. Opt. Mater. 2017, 63, 95-100. [CrossRef]

14. Milanese, D.; Ferrari, M.; Menke, Y.; Olivero, M.; Perrone, G.; Gawith, C.B.E.; Brambilla, G.; Smith, P.G.R.; Taylor, E.R. Photosensitive properties of a tin-doped sodium silicate glass for direct ultraviolet writing. Appl. Phys. Lett. 2004, 84, 3259-3261. [CrossRef]

15. Sebastiani, S.; Nunzi Conti, G.; Pelli, S.; Righini, G.C.; Chiasera, A.; Ferrari, M.; Tosello, C. Characterization of a highly photorefractive RF-sputtered $\mathrm{SiO}_{2}-\mathrm{GeO}_{2}$ waveguide. Opt. Express 2005, 13, 1696-1701. [CrossRef] [PubMed]

16. Zukauskas, A.; Matulaitien, I.; Paipulas, D.; Niaura, G.; Malinauskas, M.; Gadonas, R. Tuning the refractive index in 3D direct laser writing lithography: Towards GRIN microoptics. Laser Photonics Rev. 2015, 9, 706-712. [CrossRef]

17. Bachman, D.; Chen, Z.; Fedosejevs, R.; Tsui, Y.Y.; Van, V. Threshold for permanent refractive index change in crystalline silicon by femtosecond laser irradiation. Appl. Phys. Lett. 2016, 109, 091901. [CrossRef]

18. Brovelli, S.; Chiodini, N.; Lorenzi, R.; Lauria, A.; Romagnoli, M.; Paleari, A. Fully inorganic oxide-in-oxide ultraviolet nanocrystal light emitting devices. Nat. Commun. 2012, 3, 690. [CrossRef] [PubMed]

19. Righini, G.C.; Ferrari, M. Photoluminescence of rare-earth-doped glasses. Rivista del Nuovo Cimento 2015, 38, $1-53$.

(C) 2017 by the authors. Licensee MDPI, Basel, Switzerland. This article is an open access article distributed under the terms and conditions of the Creative Commons Attribution (CC BY) license (http://creativecommons.org/licenses/by/4.0/). 